Eco-friendly apparel acquisition

\title{
Factors motivating male consumers' eco-friendly apparel acquisition in the South African emerging market
}

Short title: Eco-friendly apparel acquisition

Keywords: Pro-environmental intent, sustainability, eco-friendly apparel/clothing, Theory of planned behaviour, Norm-activation theory

*Hanri Taljaard

Department of Consumer Science

University of Pretoria, Pretoria, SA

Nadine C. Sonnenberg

Department of Consumer Science

University of Pretoria, Pretoria, SA

Bertha M. Jacobs

Department of Consumer Science

University of Pretoria, Pretoria, SA

\section{*Corresponding Author:}

Hanri Taljaard

Department Consumer Science, Old Agricultural Building, Room 3-1.1

University of Pretoria, Pretoria, SA

Tel: +27 (12) 4204310

hanri.taljaard@up.ac.za

Private bag X20

Hatfield

0028

\section{Acknowledgements:}

I would like to acknowledge Mr. Andries Masenge, from the Department of Statistics at the University of Pretoria, for his statistical guidance and contributions surrounding the data processing and analysis of this study.

\section{Funding:}

The financial assistance of the National Research Foundation (NRF) towards this research is hereby acknowledged. Opinions expressed and conclusions arrived at, are those of the author(s) and are not necessarily to be attributed to the NRF. 


\section{Abstract}

Most role players within the South African textile and apparel industry have neglected the necessity of proenvironmental apparel behaviour and it has not yet become a familiar concept in the local context. This study focuses on male consumers' underlying motivation and intent to acquire apparel in a manner that demonstrates an ecofriendly approach. The research hypotheses and framework for this study are based on the constructs included in the Norm-Activation Theory (NAT) and the Theory of Planned Behaviour (TPB) as underlying motivational factors that contribute to pro-environmental apparel acquisition. For this study, pro-environmental approaches were conceptualised as consumers' purposive limitation/ reduction of the amount of apparel acquired as well as the evaluation and selection of apparel based on pro-environmental attributes. A quantitative, cross-sectional survey approach was used for explanatory research purposes. Male consumers (18 years and older, $n=305$ ) were reached by means of a non-probability, purposive sampling method. Respondents completed online and paper-based questionnaires that included adapted scale items for use in the local context. Results suggest that respondents are aware of the environmental consequences that are linked to the apparel industry and consumers' apparel behaviour, which then ultimately influences their behavioural intent. In contrast to studies conducted abroad, social and moral norms did not significantly influence their decisions to acquire apparel in a pro-environmental manner. Respondents' attitudes and self-efficacy (i.e. a dimension of perceived behavioural control) contributed to their intent to acquire apparel in a pro-environmental manner. Yet, controllability (another dimension of perceived behavioural control) was not a significant predictor of intent and warrants further empirical research. The findings of this study substantiate important recommendations for the development of intervention strategies to promote pro-environmental apparel behaviour in emerging market contexts such as South Africa.

\section{Keywords}

Pro-environmental intent, sustainability, eco-friendly apparel/clothing, Theory of planned behaviour, Normactivation theory 
Eco-friendly apparel acquisition

\section{Introduction}

According to the Living Planet Report (World Wild Fund, 2016) biodiversity has globally declined by $58 \%$ between 1970 and 2012. Human society is highly dependent on the consumption of fossil fuels and natural resources (Chen \& Tung, 2014). The current reality is that unless people change their way of living, two planets will be required to sustain human life by 2030. The textile and apparel industry, in particular, should reconsider its environmental impact, since textiles and clothing represent the world's second largest industry and is also one of the most polluting industries in the world (Institute of Public \& Environmental Affairs, 2012). Initiatives are required to reduce the environmental footprint spanning from the raw, natural resources to the production processes, care, maintenance as well as the disposal of products (Armstrong, Niinimäki, Kujala, Karell \& Lang, 2015). Such initiatives should not be the sole focus of more developed countries, but in fact also necessitate more stringent effort in emerging economies such as South Africa.

As an emerging economy with high levels of income inequality, much effort is devoted toward diminishing the gap between rich and poor, potentially contributing to higher consumption levels with an increasing ecological footprint and the accompanying environmental repercussions (Leibbrandt, Finn \& Woolard, 2012). South Africa is already threatened by numerous environmental problems such as the exhaustion of natural resources, loss of biodiversity and climate change (Midgley, 2007). Therefore, in growing the local economy, South Africans can no longer disregard environmental issues and concerns and should aspire to adopt more sustainable practices such as pro-environmental apparel consumption (Momberg, Jacobs \& Sonnenberg, 2012).

Pro-environmental apparel consumption can be defined as behaviours that involve environmentally friendly apparel acquisition, use, maintenance and disposal, in order to create less waste, as well as consume fewer natural resources (Hiller Connell, 2010). Consumers have various options to acquire apparel with pro-environmental attributes, such as clothing made of natural fibres or environmentally friendly textiles (e.g. organic cotton or recycled polyester), and items made of recycled materials (Shen, Zheng, Chow \& Chow, 2014). Additional "green" alternatives include apparel that is manufactured in a pro-environmental manner e.g. utilizing eco-friendly dyeing processes and/ or eco-conscious water usage during the production processes. Furthermore, pro-environmental attributes could also relate to specific designs and constructions of the apparel, for example multifunctional garments or classic styles, which allow the consumer to remain suitably dressed despite fashion-bound/ seasonal trends. With the subsequent reduction in apparel consumption, resources and energy are conserved in addition to minimizing waste and pollution that result from the initial production processes (Fletcher \& Grose, 2012). Another similar approach would be to purchase second-hand apparel, or to exchange second-hand clothing with friends and/ or family. The aforementioned options are considered environmentally sound, since it decreases the need for new apparel production, and with that the amount of apparel waste that is created (Hiller Connell, 2010). The import and export of apparel also plays a role in defining the concept of apparel with pro-environmental attributes (50/50 Human Nature, 2014). By acquiring locally produced garments, the need to import apparel and textiles could decrease, and therefore also the environmental impact associated with the transportation and distribution of such imports (Mont 
Eco-friendly apparel acquisition

\& Bleischwitz, 2007). Currently, most of the clothing found in the local market is imported (Morris \& Einhorn, 2008), which begs several questions surrounding the status quo in the local apparel industry.

In recent years (between 2009 and 2013), the South African apparel industry had a compound annual growth rate of 8.2\%, and total revenues of \$7.6 billion in 2013 (Marketline, 2014a). In addition, the South African apparel retail environment is known to be highly competitive with the continual introduction of new products representing an important growth strategy to maintain differential positioning and unique market offerings. This is especially true for South African retailers operating in the menswear segment, which contributed $\$ 2,172$ million in revenue in 2011 and accounted for 26,5\% of the South African apparel industry's aggregate value (Marketline, 2012). The menswear segment is expected to further expand and generate even higher revenues in the near future (Marketline, 2014b), which requires close scrutiny of male consumers' general buying and consumption behaviour, but also more specifically their willingness to adopt pro-environmental apparel options (Du Preez, Visser \& Zietsman, 2007).

Prior empirical research have found that gender influences environmental awareness and proenvironmental motivations (Kollmuss \& Agyeman, 2002; Mobley \& Kilbourne, 2013). Gender differences with regards to pro-environmental awareness are determined by consumers' attentiveness to knowledge, especially when considering the extent of concern for everything else around them and are ultimately the result of socialisation and life experience (Mobley \& Kilbourne, 2013). Research has revealed that the attitude and behaviour of women regarding the environment tend to be stronger than that of men; they are significantly more concerned about the environment than males (Mitchell \& Walsh, 2004; Mostafa, 2007). This may be attributed to the notion that females are more expressive in terms of their emotions, the social standards they set, as well as having a stronger "ethic of care". Males, however, tend to be more independent and competitive with regards to socialisation and values (Lee, 2009). Together with that, marketers have depicted men as being more "sensitive" in the last few years (Solomon \& Rabolt, 2004) and they seem to have evolved regarding their underlying intentions and buying behaviours (Keiser \& Garner, 2008). Specifically, male consumers have become more prone to investigate apparel options before they purchase specific garments, which in itself provide them with more experience and knowledge regarding apparel (Bakewell, Mitchell \& Rothwell, 2006; Du Preez et al., 2007). Notwithstanding the apparent importance of focusing more attention toward investigating male apparel consumption behaviour (Bakewell \& Mitchell, 2004; Otnes \& McGrath, 2001), empirical evidence still seem sparse, especially in the local context (Du Preez et al., 2007).

In addition to the impact of gender, research pertaining to pro-environmental behaviour has shown that, despite consumers' awareness of the environmental issues associated with their apparel consumption, they are hesitant, or unwilling to purchase apparel with pro-environmental attributes, or acquire apparel from environmentally preferable sources (Hiller Connell, 2010; Joung \& Park-Poaps, 2013; Kollmuss \& Agyeman, 2002). This attitude-behaviour gap has been the topic of much debate in environmental consumerism, with various contributing factors identified as the underlying basis of such inconsistency (Ha-Brookshire \& Norum, 2011). Some of the influencing factors identified by previous research included the absence of environmental awareness 
Eco-friendly apparel acquisition

(Momberg et al., 2012), inconvenience (Kozar \& Hiller Connell, 2013), limited knowledge regarding environmental effects of apparel consumption (Hiller Connell, 2010), a lack of awareness of the available products and services (Momberg et al., 2012), perceived consumer effectiveness (Hustvedt \& Dickson, 2009), social and cultural influences (Kozar \& Hiller Connell, 2013), while economic circumstances also seem to influence consumers in some way (Jackson, 2005). Researchers in the environmental domain have long since acknowledged that pro-environmental motivation and intent may not necessarily translate into environmentally responsible behaviour due to various contextual circumstances (Tanner, Kaiser \& Wölfing Kast, 2004). However, research showed that an understanding of consumers' internal motivation to act in a pro-environmental manner is the first step towards the development and assessment of environmental intervention programmes and marketing campaigns (Bator \& Cialdini, 2000; Steg \& Vlek, 2009; Zelezny \& Schultz, 2000). In this regard, the development of models regarding the explanation and prediction of pro-environmental behaviour has become an important issue of environmental research. Also, literature on the different theoretical frameworks and factors that could influence pro-environmental patterns is increasing (Bamberg \& Möser, 2007; Park \& Ha, 2014; Tonglet, Phillips \& Read, 2004).

\section{Theoretical background and hypotheses}

One of the most significant problems that modern society has to realise is that their behaviour is detrimental to the environment (Bamberg, Hunecke \& Blöbaum, 2007). Humans live on a finite planet, with limited natural resources, a rapidly growing population, and a constant increase in the degradation of the natural environment (Arden-Clarke, 2014). As such, a conscious shift to practice more sustainable production and consumption is needed in order to contribute positively to the notion of "living better, with less" (Arden-Clarke, 2014). This notion is espoused by proenvironmental behaviour that can either be explained as an action motivated by self-interest or as the concern for others with underlying pro-social motives (Bamberg et al., 2007). Various theoretical frameworks have been developed in this regard (Park \& Ha, 2014; Tang, Chen \& Luo, 2011; Tonglet et al., 2004). When viewing proenvironmental behaviour from a pro-social perspective, researchers tend to prefer Schwartz's (1977) NormActivation Theory (NAT) (Bamberg et al., 2007; Schwartz, 1977). Actions motivated by self-interest are often explored by the use of rational choice models such as Ajzen's (1991) Theory of Planned Behaviour (TPB) (Ajzen, 1991). Based on the argument that pro-environmental behaviour includes a degree of self-interest and pro-social motives (Park \& Ha, 2014; Wall, Devine-Wright \& Mill, 2007), researchers increasingly propose combining the variables from the NAT and the TPB. This enables a more comprehensive understanding of pro-environmental behaviour in terms of various underlying motivational factors surrounding the engagement of specific behaviours. However, to date most studies have focused on consumer populations other than South Africa and may include different perspectives and conclusions regarding consumers' behaviour due to demographic differences. This could add to the intricacy of understanding pro-environmental behaviour, and more specifically pro-environmental apparel consumption, in the local emerging context. 
Eco-friendly apparel acquisition

In addressing the main aim of this study i.e. to determine male consumers' pro-environmental motivation and intent to acquire apparel in an eco-friendly manner (i.e. to acquire less or acquire apparel with proenvironmental attributes) within the South African emerging context, constructs related to the NAT and TPB were combined as proposed in existing literature. Prior empirical research has suggested that an awareness of environmental consequences and moral norms (as postulated in NAT) will influence individuals' willingness/ intent to engage in pro-environmental behaviour (Bamberg \& Möser, 2007; Wall et al., 2007). Several studies have also established the positive relationship between social norms, attitude and perceived behavioural control in determining pro-environmental intent as postulated in the TPB (Bamberg \& Möser, 2007; Park \& Ha, 2014; Wall et al., 2007). Ajzen (2002) and other researchers have argued that perceived behavioural control, in particular, may incorporate dimensions of perceived self-efficacy and controllability (Ajzen, 2002; Bamberg \& Möser, 2007; Park \& Ha, 2014; Tonglet et al., 2004).

According to Ajzen (2002), the notion of "locus of control" is an aspect closely related to perceived selfefficacy and can be defined as an individual's perception of whether they are able to change issues such as 'living sustainably' through their own individual behaviour, without it seeming insignificant (Kollmuss \& Agyeman, 2002). This perception could be positively applied once consumers come to the realisation that every individual effort they put in to being pro-environmental (however insignificant it may seem), could ultimately contribute to a bigger cause which relates to conserving natural resources. Such an example could be the simple action of buying eco-friendly clothing or limiting their apparel purchases. This, in turn, encapsulates numerous positive aspects for the environment. Self-efficacy is thus an important concept to consider when investigating consumers' intentions to act in a pro-environmental manner. Controllability, on the other hand, can be explained as the views consumers possess about having control over their behaviour, i.e. that the actual performance or non-performance of a specific behaviour is ultimately up to them (Ajzen, 2002). Although consumers may be aware of the environmental and sustainability issues, or even have a positive attitude towards pro-environmental apparel acquisitions, it does not necessarily mean that they will engage in such behaviour, because of certain external factors, such as lack of opportunities, skills or resources (Barr, 2007). Controllability may thus represent an important dimension in determining consumers' intent and ultimate engagement in pro-environmental actions.

Based on existing empirical evidence and the aforementioned arguments, the following hypotheses were developed for this study:

H1: Awareness of the environmental consequences (related to apparel consumption) has a positive effect on male consumers' pro-environmental intent to engage in eco-friendly apparel acquisition.

H2: Social norms have a positive effect on male consumers' pro-environmental intent to engage in eco-friendly apparel acquisition.

H3: Moral norms have a positive effect on male consumers' pro-environmental intent to engage in eco-friendly apparel acquisition. 
H4: Attitudes have a positive effect on male consumers' pro-environmental intent to engage in eco-friendly apparel acquisition.

H5 Perceived behavioural control has a positive effect on male consumers' pro-environmental intent to engage in eco-friendly apparel acquisition. More specifically,

H5a: Self-efficacy (as a dimension of perceived behavioural control) has a positive effect on male consumers' pro-environmental intent to engage in eco-friendly apparel acquisition.

H5b: Controllability (as a dimension of perceived behavioural control) has a positive effect on male consumers' pro-environmental intent to engage in eco-friendly apparel acquisition.

\section{Method}

A cross-sectional quantitative research approach was followed, incorporating a survey design for explanatory research purposes. Male consumers were reached by means of non-probability, purposive sampling methods (Strydom, 2011). Male consumers were specifically targeted for the purposes of this study because limited empirical evidence exists regarding their pro-environmental intent to acquire apparel that would have positive environmental consequences. Table 1 provides a summary of the other demographic characteristics of this sample $(n=305)$. Participants were 18 years and older with most of them between the ages of 18 and 24 years (70\%). South Africa has a predominantly young population: $46.4 \%$ of the country's population is 24 years and younger (Indexmundi, 2017), who could be described as being socially and environmentally conscious. There was no prerequisite in terms of population groups; however, the majority were Caucasian (73\%) and had completed their schooling education with $45 \%$ in possession of some form of post schooling qualification. Most respondents resided in Pretoria (74\%), which is classified as one of the three most prominent metropolitan municipalities in Gauteng. Respondents earned an approximate individual income less than R 5000 or $\$ 391$ per month (60\%). Due to the fact that non-probability sampling was used to collect the data for the research study, the results cannot be generalised (Strydom, 2011).

Table 1 Demographic profile of the respondents

\begin{tabular}{lcl}
\hline Variables & Frequency & Percentage \\
\hline Age $(n=305)$ & & \\
$18-24$ & 214 & 70.2 \\
$25-30$ & 52 & 17.0 \\
$\quad 31$ or older & 39 & 12.8 \\
Race $(n=305)$ & & \\
$\quad$ Caucasian & 222 & 72.8 \\
$\quad$ Black \& other & 83 & 27.2 \\
Academic level $(n=305)$ & & \\
$\quad$ Grade 12 / Matric & 167 & 54.8 \\
$\quad$ Post matriculation degree/diploma & 138 & 45.2 \\
Area of residence $(n=305)$ & & \\
$\quad$ Pretoria & 226 & 74.1
\end{tabular}


Eco-friendly apparel acquisition

\begin{tabular}{lrr} 
Johannesburg & 57 & 18.7 \\
Other & 22 & 7.2 \\
Income per month $(n=305)$ & & \\
Less than R 5 000 & 181 & 59.3 \\
R 5 000-R 25 000 & 85 & 27.9 \\
More than R 25 000 & 39 & 12.8 \\
\hline
\end{tabular}

Primary data were gathered by means of self-administered structured questionnaires that were distributed among male consumers in a number of ways, including a paper-based format and via online electronic formats such as e-mails and social networks. The online survey was administered by means of "SurveyMonkey" and was electronically sent out as a link. E-mails, with a linked attachment of the full colour version of the questionnaire were sent out to prospective participants who complied with the inclusion criteria. With regards to social networks, the questionnaire was also made available to prospective participants via Facebook with a link through which they could gain access to the questionnaire enabling them online completion. Due to face-to-face interactions during the collection of data via paper-based questionnaires as well as the fact that the online "SurveyMonkey" system only accepted the submission of completed questionnaires, a $100 \%$ response rate was achieved. Once all of the data were gathered it was converted into manageable formats. All data collected, irrespective of whether it was captured manually or electronically, was coded and captured into electronic format.

\section{Results, findings and discussions}

Multiple linear regression analysis was used to explain the underlying associations between the various motivational constructs and male respondents' pro-environmental intent. The overall model was statistically significant and the null hypothesis, which states that the dependent variable (male consumers' behavioural intent) is not a function of the independent variables (i.e. awareness of consequences, social norms, attitudes, moral norms, self-efficacy and control over the availability of eco-friendly apparel options) was rejected. It was surmised that the independent variables, collectively, contribute significantly towards explaining the dependent variable.

The overall explanatory power of the regression model was determined by interpreting $\mathrm{R}^{2}$, which is the ratio that measures the variance of the dependent variable that is explained by the independent variables (Mazzocchi, 2008). Thus, the explanatory power of the regression model becomes larger, as the value of $\mathrm{R}^{2}$ become higher (Hair, Black, Babin \& Anderson, 2014). Table 2 indicates that $49.4 \%$ of the variability in the dependent variable (behavioural intent) is explained by the independent variables (awareness of consequences, social norms, attitude, moral norms, self-efficacy and control over the availability of eco-friendly apparel) (Norušis, 2006). As indicated in Table 2 , the adjusted $\mathrm{R}^{2}$ indicates that $48.4 \%$ of the variations in behavioural intent to acquire eco-friendly apparel in a pro-environmental manner can be explained by the combination of the independent variables. This value is preferable as it takes the number of variables into consideration. According to Mazzocchi (2008), the acceptable 
Eco-friendly apparel acquisition

model should explain at least $40 \%$ of the original variability. Based on such criteria, it is evident that this model is acceptable. Furthermore Figure 1 includes a histogram of the "Regression Standardised Residual" in which the data has a normal, symmetric distribution.

The adjusted $\mathrm{R}^{2}$ for this model is $48.4 \%$, which implies that there is still scope for further explanation. In this regard, researchers' arguments relating to the attitude-behaviour gap (i.e. inconsistency between underlying motivational factors and actual behaviour) might be taken into account to offer more insight (Ha-Brookshire \& Norum, 2011; Kozar \& Hiller Connell, 2013). It is often argued that additional variables such as contextual circumstances may impact on actual behaviour which is not encapsulated in consumers' intent and underlying motivation.

Table 2 Model Summary

\begin{tabular}{ccccc}
\hline Model & $R$ & $R^{2}$ & Adjusted $R^{2}$ & Std. Error of the Estimate \\
\hline 1 & $.703^{a}$ & .494 & .484 & .37916 \\
\hline
\end{tabular}

a. Predictors: (Constant), Controllability Availability of eco-friendly apparel, Attitude, Social norms, Self -efficacy, Awareness of Consequences, Moral norms

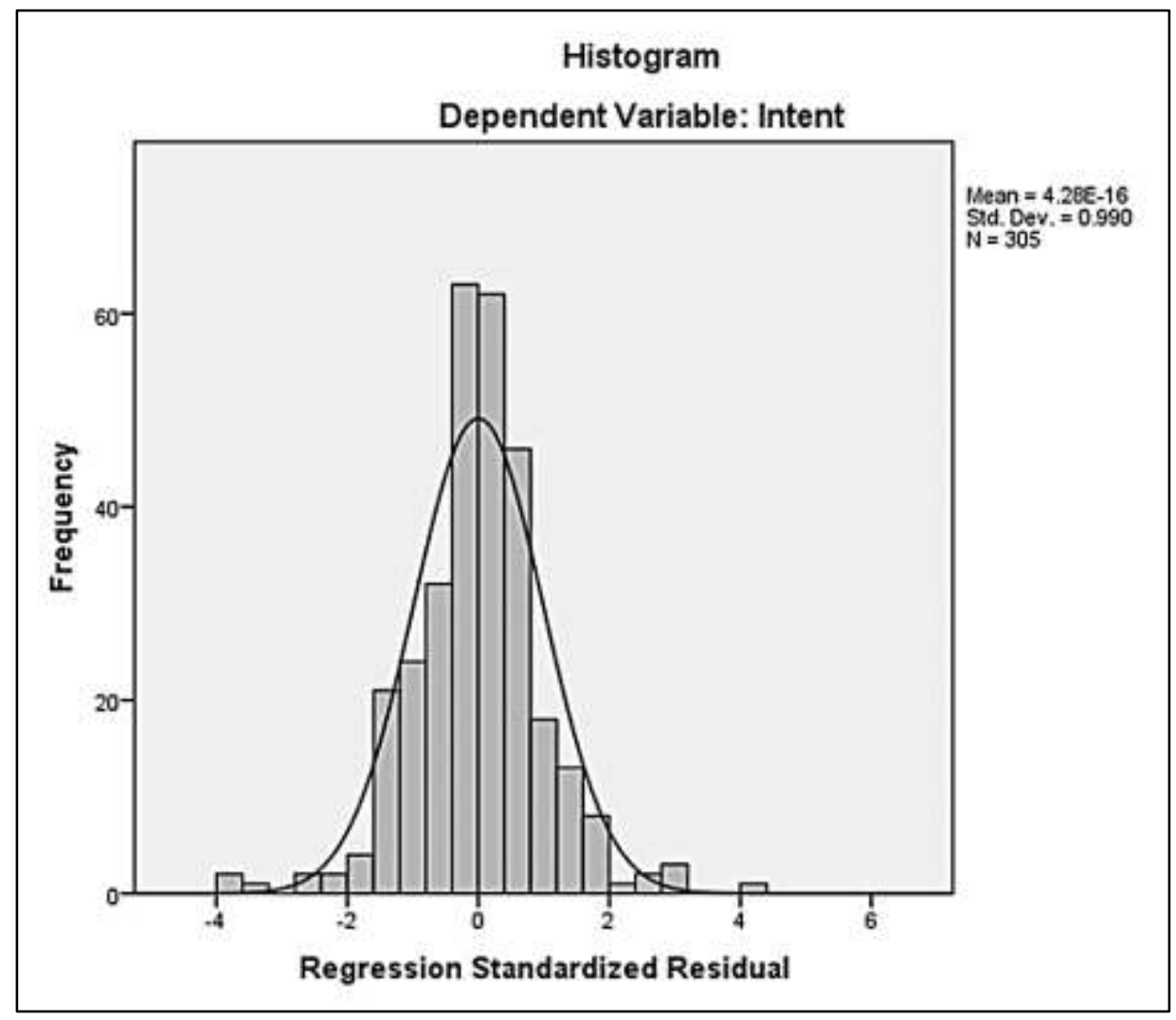

Figure 1 Normal Distribution Histogram: Mean = 4.28E-16; Standard Deviation (Std. Dev.) = 0.990; Sample (N)=305. 
The regression coefficients provide information regarding the strength of the relationship between the independent variables and the dependent variable, and secondly, it also indicates the type of relationship. Based on the results reported in Table 3 , it can be concluded that self-efficacy $(\beta=0.293 ; t=5.762, p<0.0001)$ and attitudes $(\beta=0.274 ; t=4.975, p<0.0001)$ are statistically the two most significant predictors of behavioural intent. Hypotheses 4 and $\mathrm{H} 5$ a were thus supported. With regards to the $\mathrm{p}$-value or significance level that should be smaller than 0.05 , awareness of consequences $(\beta=0.180 ; t=3.485, p<0.05)$ can also be classified as a significant predictor of behavioural intent in terms of acquiring eco-friendly apparel in a pro-environmental manner. Hypothesis 1 was therefore also supported. However, social norms $(\beta=0.074 ; t=1.372, p<0.171)$, moral norms $(\beta=0.110 ; t=1.729$, $p<0.085)$, and controllability $(\beta=-0.047 ; t=-1.075, p<0.283)$ were not significant in predicting male consumers' pro-environmental intent to acquire eco-friendly apparel in a South Africa emerging market context. Hypotheses 2 , 3 and $5 b$ were thus not supported.

Table 3 Regression Coefficients ${ }^{a}$

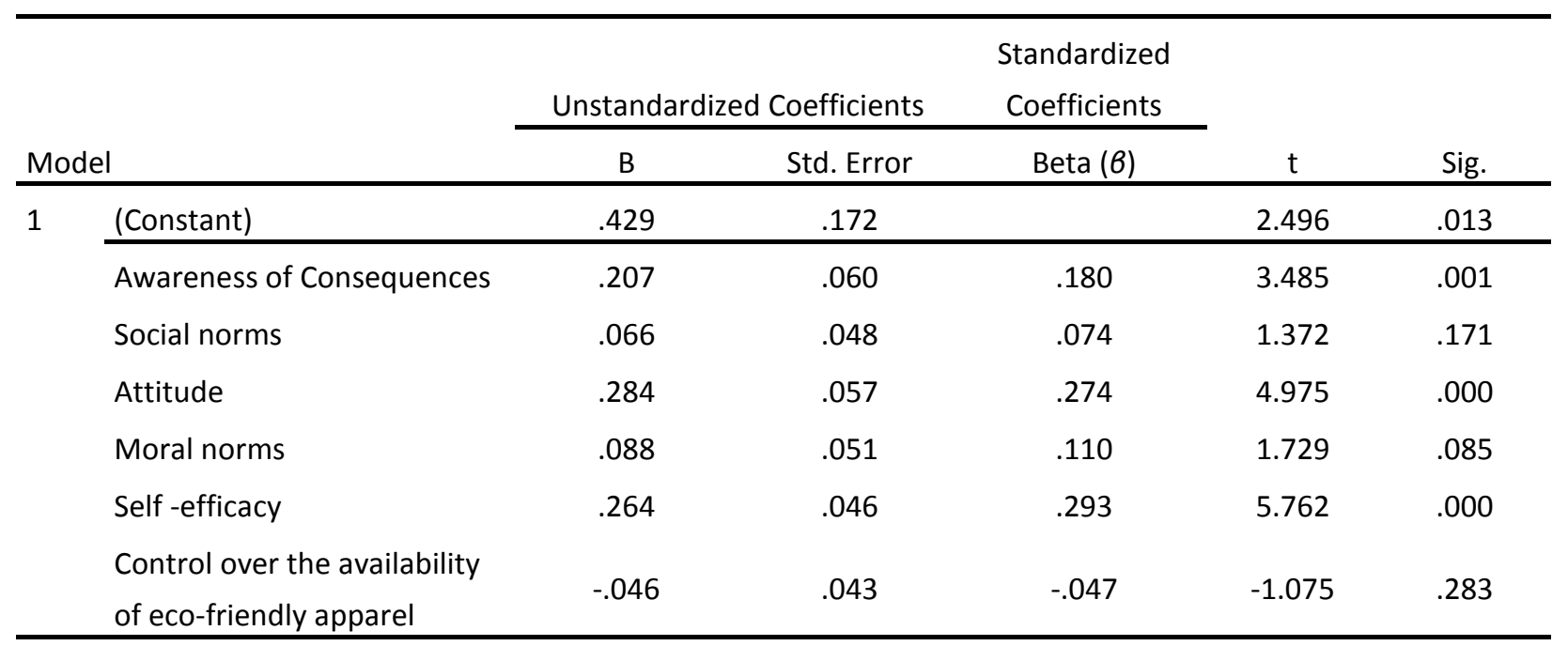

a. Dependent Variable: Behavioural intent

The significant association between an awareness of consequences and intent is supported by the findings of various previous studies (Bamberg \& Möser, 2007; Park \& Ha, 2014; Wall et al., 2007). It can thus be assumed that for male respondents, an awareness of consequences relating to the acquisition of eco-friendly clothing fulfils a significant role in determining their pro-environmental intent. Attitude is also deemed significant in terms of predicting behavioural intent, which emulates the results of studies conducted by Kollmuss \& Agyeman (2002), Bamberg \& Möser (2007) as well as Park \& Ha (2014). Furthermore, self-efficacy was also found to contribute significantly to behavioural intent, which corresponds with the results of Armitage and Connor's (2001) metaanalysis of TPB studies. However, the fact that social norms and moral norms were not significant predictors of the respondents' overall behavioural intent was not as expected. Most literature to date indicates moral norms are 
Eco-friendly apparel acquisition

positively associated with pro-environmental intent and behaviour (Bamberg \& Möser, 2007; Park \& Ha, 2014; Wall et al., 2007). Social norms, for the most part, are reported to also have a positive association with intent and behaviour, although some debate has ensued in recent years. Some studies (Bamberg \& Möser, 2007; Park \& Ha, 2014) have deemed it significant in terms of exerting an indirect influence on intentions through attitude, moral norms and perceived behavioural control, while other studies (Armitage \& Conner, 2001; Wall et al., 2007) question its overall significance as predictors of intentions. In some cases, researchers have argued that social norms rarely predict intentions and have altogether removed it as a significant predictor of intent and behaviour (Sparks, Shepherd, Wieringa \& Zimmermanns, 1995). Armitage \& Conner (2001) provide some support for this assumption as social norms were found to be the least significant determinants of intent in their extensive meta-analysis of TPB studies. Wall et al. (2007) suggest that social norms' insignificant influence could be explained by the inclusion of moral norms that capture perceived social pressures. However, in this study both the moral and social norms were deemed to be insignificant predictors of intent.

Gender may be the key issue in explaining the aforementioned results as most prior studies included both males and females or exclusively focused on females in explaining the association between norms and proenvironmental intent. In contrast, this study exclusively focused on male consumers. As mentioned earlier, gender perceptions of pro-environmental issues are determined by attentiveness to knowledge, concern for other people and other species, and are the result of socialisation and life experiences (Mobley \& Kilbourne, 2013). Moreover, prior research has also revealed that men are less concerned about the environment than women and will not easily change their behaviour to benefit the environment (Mitchell \& Walsh, 2004; Mostafa, 2007). Based on the findings of this study, norms could represent a central construct for further investigation in terms of gender differences. This could be supported by the notion that males are controlled by certain goals, which form part of assertion and mastery, rather than communal goals like affiliation and development of harmonious relations (Solomon \& Rabolt, 2004) that are imperative in the pursuit of sustainable development. Also, males are considered less expressive in terms of their emotions, social standards and "ethic of care" and tend to be independent (Lee, 2009). They may therefore not openly express their personal norms and deem social norms as less important motives to engage in pro-environmental apparel behaviour in the local South African emerging market context. Based on the aforementioned conclusions, it is apparent that social and personal norms require further empirical investigation specifically in terms of gender differences and pro-environmental apparel behaviour.

Lastly, the negative association between controllability and behavioural intent $(\beta=-0.047 ; t=-1.075, p<$ 0.283 ) is also worth noting. Various factors surround the complexity of perceived behavioural control as a construct and more specifically, controllability, as a further dimension of this construct. With regard to this research study, perceived behavioural control was purposively extended and separated into two sub-components, namely perceived self-efficacy (which is related to capability aspects), and controllability (which is related to opportunities aspects) (Tang et al., 2011). Items that have to do with either the ease or difficulty of a performance, or the confidence that a consumer has in his/her abilities to perform a certain task, usually measure the perceived self-efficacy, whereas 
items concerning the control of a certain behaviour usually measures the controllability (Ajzen, 2002). Armitage \& Conner (2001) concluded that the effects of these two dimensions of perceived behavioural control may vary depending on whether it is associated with intentions or actual behaviour.

In this study, self-efficacy proved to be a positive, significant predictor of behavioural intent. The same cannot be said for controllability, but as explained by Armitage \& Conner (2001) its potential impact on actual behaviour should not be disregarded. Various circumstances may contribute to consumers' belief that they do not have control over factors that impact on their eventual ability to engage in eco-friendly behaviour despite their best intent (Tonglet et al., 2004) e.g. they might not be convinced about the availability of eco-friendly apparel options. In fact, the availability of eco-friendly apparel in local South African stores remain limited, which is further inhibited by cheaper imports that make eco-friendly apparel alternatives less appealing to the mass population, especially if such eco-friendly options are more expensive (PwC and Economist Intelligence Unit, 2012). Where durable and classical styles are concerned, male respondents may lack the necessary understanding and knowledge of such options. Previous research has argued that the dependence of the behaviour on motivational variables depends on the difficulty, price or time of the type of behaviour (Sonnenberg, 2014; Tanner et al., 2004). The argument brought forward is that the more time-consuming and expensive the behaviour becomes, the higher the risk and the less rewarding it becomes to try and behave accordingly, which makes the dependence of the behaviour weaker on the motivational variables. In terms of this study's findings, it may be argued that the factors that extend beyond the male consumers' personal domain, such as the above-mentioned availability of eco-friendly apparel, will remain significant in facilitating consumers' eventual enactment of their pro-environmental intent. Controllability, and its association to certain external factors, should thus remain the focus of further exploration especially in terms of male consumers' actual pro-environmental behaviour rather than their behavioural intent.

\section{Limitations and recommendations for future research}

The following opportunities for further research were identified during the research process, namely that by amending the non-probability sampling method to a probability sampling method, a better representative sample can be achieved and generalisations can be made. In order to better inform marketing campaigns and intervention initiatives, a more representative sample would be needed to be able to make conclusions about South African male consumers in general. However, it is not always easy to attain representative data in developing countries such as South Africa due to the lack of sampling frames (Burgess \& Steenkamp, 2006). Response bias is also a continual concern in terms of environmentally related studies (Bamberg \& Möser, 2007). Respondents have a tendency to overrate their willingness in terms of pro-environmental options in relation to their actual behaviour concerning these issues (Steg \& Vlek, 2009). In terms of this research study, only the intentions of the respondents were measured with regards to their pro-environmental apparel acquisitions, so therefore response bias might be inevitable. However, future research could include the actual behaviour as well to determine the pro-environmental apparel acquisition behaviour of South African consumers and determine to what extent the motivational factors 
influence the intent and the eventual behaviour. A need also exists in the research for a more in-depth understanding of how and why consumers react towards pro-environmental notions such as eco-friendly apparel products and the limitation of acquiring apparel to help save the environment, and what influence the socio-psychological factors have on their intentions and behaviours. Therefore, future research could explore and describe these issues by making use of qualitative research methods to gain insight regarding these matters. Qualitative approaches are especially useful in emerging contexts where methodological challenges, such as incomplete questionnaires due to lower literacy, are often experienced during survey-based projects (Burgess \& Steenkamp, 2006; Chatterjee, 2008).

With regards to the data analyses, several issues were identified in terms constructs and scale development. To build forth on the results of this study and limit these difficulties in the future, intensive instrument development can be pursued to make sure that all the items being used in the data collection process is clear and understandable as well as provide researchers with data that is easily interpreted. Furthermore, multiple regression analysis was used to interpret the results and analyse the relationship between the dependent variable (i.e. behavioural intent) and the independent variables (i.e. awareness of consequences, social norms, attitude, moral norms, self-efficacy and controllability). However, future research could benefit from data analysis techniques such as structural equation modelling (SEM) that could provide the researcher with a more in-depth understanding of the constructs that were used in the conceptual framework and how much they relate to each other to ultimately influence the intent or behaviour. It could also be used to explore the relationship and relevance of the various variables or constructs (Mazzocchi, 2008) and enable researchers to further interpret and improve on the proposed conceptual framework.

\section{References}

50/50 Human Nature. (2014). Woolworths Recycled Jeans. Youtube. Retrieved from http://www.youtube.com/watch?v=JGiwbCTd2C4 (accessed on 26 May 2014).

Ajzen, I. (1991). The theory of planned behavior. Organizational Behavior and Human Decision Processes, 50, 179211.

Ajzen, I. (2002). Perceived behavioral control, self-efficacy, locus of control, and the theory of planned behavior. Journal of Applied Social Psychology, 32, 665-683.

Arden-Clarke, C. (2014). Executive perspective: Consumption and Production for a finite planet. Retrieved from http://sustainability.thomsonreuters.com/2014/06/26/executive-erspective-sustainable-consumptionproduction-finite-planet/ (accessed on 7 July 2014).

Armitage, C. J. \& Conner, M. (2001). Efficacy of the theory of planned behaviour: A meta-analytic review. British Journal of Social Psychology, 40, 471-499.

Armstrong, C. M., Niinimäki, K., Kujala, S., Karell, E. \& Lang, C. (2015). Sustainable product-service systems for clothing: exploring consumer perceptions of consumption alternatives in Finland. Journal of Cleaner Production, 97, 30-39. 
Eco-friendly apparel acquisition

Bakewell, C. \& Mitchell, V.-W. (2004). Male consumer decision-making styles. The International Review of Retail, Distribution and Consumer Research, 14, 223-240.

Bakewell, C., Mitchell, V.-W. \& Rothwell, M. (2006). UK Generation Y male fashion consciousness. Journal of Fashion Marketing and Management: An International Journal, 10, 169-180.

Bamberg, S., Hunecke, M. \& Blöbaum, A. (2007). Social context, personal norms and the use of public transportation: Two field studies. Journal of Environmental Psychology, 27, 190-203.

Bamberg, S. \& Möser, G. (2007). Twenty years after Hines, Hungerford, and Tomera: A new meta-analysis of psychosocial determinants of pro-environmental behaviour. Journal of Environmental Psychology, 27, 14-25.

Barr, S. (2007). Factors influencing environmental attitudes and behaviors: A UK case study of household waste management. Environment and Behavior, 39, 435-473.

Bator, R. \& Cialdini, R. (2000). The application of persuasion theory to the development of effective proenvironmental public service announcements. Journal of Social Issues, 56, 527-542.

Burgess, S. M. \& Steenkamp, J.-B. E. (2006). Marketing renaissance: How research in emerging markets advances marketing science and practice. International Journal of Research in Marketing, 23, 337-356.

Chatterjee, D. P. (2008). Oriental disadvantage versus occidental exuberance: Appraising environmental concern in India-A case study in a local context. International Sociology, 23, 5-33.

Chen, M.-F. \& Tung, P.-J. (2014). Developing an extended theory of planned behavior model to predict consumers' intention to visit green hotels. International Journal of Hospitality Management, 36, 221-230.

Du Preez, R., Visser, E. \& Zietsman, L. (2007). Profiling male apparel consumers: lifestyle, shopping orientation, patronage behaviour and shopping mall behaviour. Management Dynamics: Journal of the Southern African Institute for Management Scientists, 16, 2-19.

Fletcher, K. \& Grose, L. (2012). Fashion \& sustainability: Design for Change. London, England: Laurence King.

Ha-Brookshire, J. E. \& Norum, P. S. (2011). Willingness to pay for socially responsible products: case of cotton apparel. Journal of Consumer Marketing, 28, 344-353.

Hair, J. F., Jr., Black, W. C., Babin, B. J. \& Anderson, R. E. (2014). Multivariate data analysis. 3rd edn. Harlow: Pearson Education Limited.

Hiller Connell, K. Y. (2010). Internal and external barriers to eco-conscious apparel acquisition. International Journal of Consumer Studies, 34, 279-286.

Hustvedt, G. \& Dickson, M. A. (2009). Consumer likelihood of purchasing organic cotton apparel: Influence of attitudes and self-identity. Journal of Fashion Marketing and Management: An International Journal, 13, 49-65.

Indexmundi. (2017). South Africa Demographics Profile $2017 . \quad$ Retrieved from http://www.indexmundi.com/south africa/demographics profile.html (accessed on 24 July 2017).

Institute of Public \& Environmental Affairs. (2012). Cleaning up the Fashion Industry. Retrieved from http://www.ipe.org.cn/Upload/Report-Textiles-One-EN.pdf (accessed on 4 February 2014). 
Eco-friendly apparel acquisition

Jackson, T. (2005). Motivating sustainable consumption: A review of evidence on consumer behaviour and behavioural change. Centre for Environmental Strategy, University of Surrey.

Joung, H. M. \& Park-Poaps, H. (2013). Factors motivating and influencing clothing disposal behaviours. International Journal of Consumer Studies, 37, 105-111.

Keiser, S. J. \& Garner, M. B. (2008). Beyond design: The synergy of Apparel Product Development. 2nd edn. New York: Fairchild Publications.

Kollmuss, A. \& Agyeman, J. (2002). Mind the gap: why do people act environmentally and what are the barriers to pro-environmental behavior? Environmental Education Research, 8, 239-260.

Kozar, J. M. \& Hiller Connell, K. Y. (2013). Socially and environmentally responsible apparel consumption: knowledge, attitudes, and behaviors. Social Responsibility Journal, 9, 315-324.

Lee, K. (2009). Gender differences in Hong Kong adolescent consumers' green purchasing behavior. Journal of Consumer Marketing, 26, 87-96.

Leibbrandt, M., Finn, A. \& Woolard, I. (2012). Describing and decomposing post-apartheid income inequality in South Africa. Development Southern Africa, 29, 19-34.

Marketline. (2012). Apparel Retail in South Africa. Retrieved from http://www.marketlineinfo.com (accessed on 20 August 2013).

Marketline. (2014a). Apparel Retail in South Africa. Retrieved from http://store.marketline.com/Product/south africa apparel retail?productid=MLIP1366-0042 (accessed on 11 August 2014).

Marketline. (2014b). South Africa - Menswear. Retrieved from http://store.marketline.com/Product/south africa menswear?productid=MLIP1295-0023 (accessed on 11 February 2015).

Mazzocchi, M. (2008). Statistics for Marketing and Consumer Research. Los Angeles: Sage Publications.

Midgley, G. (2007). Climate Change. Environpaedia: Rethinking reality. Retrieved from http://www.enviropaedia.com/topic/default.php?topic id=308 (accessed on 4 February 2014).

Mitchell, V.-W. \& Walsh, G. (2004). Gender differences in German consumer decision-making styles. Journal of Consumer Behaviour, 3, 331-346.

Mobley, C. \& Kilbourne, W. (2013). Gender Differences in Pro-Environmental Intentions: A Cross-National Perspective on the Influence of Self-Enhancement Values and Views on Technology. Sociological Inquiry, 83, 310-332.

Momberg, D., Jacobs, B. \& Sonnenberg, N. (2012). The role of environmental knowledge in young female consumers' evaluation and selection of apparel in South Africa. International Journal of Consumer Studies, 36, 408-415.

Mont, O. \& Bleischwitz, R. (2007). Sustainable consumption and resource management in the light of life cycle thinking. European Environment, 17, 59-76. 
Morris, M. \& Einhorn, G. (2008). Globalisation, welfare and competitiveness: the impacts of Chinese imports on the South African clothing and textile industry. Competition \& Change, 12, 355-376.

Mostafa, M. M. (2007). Gender differences in Egyptian consumers' green purchase behaviour: the effects of environmental knowledge, concern and attitude. International Journal of Consumer Studies, 31, $220-229$.

Norušis, M. J. (2006). SPSS 14.0 guide to data analysis. Upper Saddle River, NJ: Prentice Hall

Otnes, C. \& McGrath, M. A. (2001). Perceptions and realities of male shopping behavior. Journal of Retailing, 77, 111-137.

Park, J. \& Ha, S. (2014). Understanding consumer recycling behavior: Combining the theory of planned behavior and the norm activation model. Family and Consumer Sciences Research Journal, 42, 278-291.

PwC and Economist Intelligence Unit. (2012). South African retail and consumer products outlook. Retrieved from http://www.pwc.co.za/en ZA/za/assets/pdf/retail-and-consumer-products-outlook-2012-2016.pdf (accessed on 24 February 2015).

Schwartz, S. H. (1977). Normative influences on altruism. Advances in Experimental Social Psychology, 10, $221-279$.

Shen, B., Zheng, J.-H., Chow, P.-S. \& Chow, K.-Y. (2014). Perception of fashion sustainability in online community. The Journal of the Textile Institute, 105, 971-979.

Solomon, M. R. \& Rabolt, N. J. (2004). Consumer Behavior in Fashion. Upper Saddle River, N.J.: Prentice Hall.

Sonnenberg, N. (2014). The significance of environmental issues and contextual circumstances during South African consumers' pre-purchase evaluation of major household appliances. Phd Doctoral thesis. Pretoria, South Africa: University of Pretoria. Retrieved from http://hdl.handle.net/2263/46278 (accessed on 15 January 2013).

Sparks, P., Shepherd, R., Wieringa, N. \& Zimmermanns, N. (1995). Perceived behavioural control, unrealistic optimism and dietary change: An exploratory study. Appetite, 24, 243-255.

Steg, L. \& Vlek, C. (2009). Encouraging pro-environmental behaviour: An integrative review and research agenda. Journal of Environmental Psychology, 29, 309-317.

Strydom, H. (2011). Sampling in the quantitative paradigm. In: De Vos, A. S., Strydom, H., Fouche, C. B. \& Delport, C. S. L. (eds.) Research at Grass Roots: For the social sciences and human service professions. 4th edn. Pretoria, Hatfield: Van Schaik Publishers.

Tang, Z., Chen, X. \& Luo, J. (2011). Determining socio-psychological drivers for rural household recycling behavior in developing countries: A case study from Wugan, Hunan, China. Environment and Behavior, 43, 848-877.

Tanner, C., Kaiser, F. G. \& Wölfing Kast, S. (2004). Contextual conditions of ecological consumerism: A foodpurchasing survey. Environment and Behavior, 36, 94-111.

Tonglet, M., Phillips, P. S. \& Read, A. D. (2004). Using the Theory of Planned Behaviour to investigate the determinants of recycling behaviour: a case study from Brixworth, UK. Resources, Conservation and Recycling, 41, 191-214. 
Eco-friendly apparel acquisition

Wall, R., Devine-Wright, P. \& Mill, G. A. (2007). Comparing and combining theories to explain proenvironmental intentions: The case of commuting-mode choice. Environment and Behavior, 39, 731-753.

World Wild Fund. (2016). Living Planet Report. Retrieved from https://www.worldwildlife.org/pages/living-planetreport-2016 (accessed on 12 May 2017).

Zelezny, L. C. \& Schultz, P. (2000). Psychology of promoting environmentalism: promoting environmentalism. Journal of Social Issues, 56, 365-371. 